\title{
Tingginya Angka Kecelakanaan Akibat Pembangunan Jalur 3 Di Kota Bangko
}

\author{
Nadra Arsyad ${ }^{1}$, Jihan Melasari ${ }^{2}$, Dicki Aditya ${ }^{3}$ \\ Fakultas Teknik, Universitas Putra Indonesia "YPTK" Padang ${ }^{1,2,3}$ \\ Email: nadra.arsyad@gmail.com ${ }^{1}$ jihan_melasari@upiyptk.ac.id ${ }^{2}$, dikibangko57@gmail.com ${ }^{3}$ \\ DOI: http://dx.doi.org/10.31869/rtj.v5i1.2941
}

\begin{abstract}
Masalah kecelakaan lalu lintas pada jalur tiga dikota Bangko selama kurun waktu 20172020. Tujuan penelitian ini adalah Mengetahui penyebab terjadinya kecelakaan lalu lintas pada jalur tiga dikota Bangko dan Menentukan black Spot. Penelitian ini adalah penelitian deskriptif retrospektif data sekunder dari laporan kecelakaan lalu lintas pada jalur tiga dikota Bangko dan data primer didapat langsung kelapangan. Empat faktor yaitu, faktor manusia sebanyak 134 kasus, faktor sarana sebanyak 66 kasus, faktor prasarana sebanyak 18 kasus dan faktor cuaca sebanyak 10 kasus, terdapat beberapa keselahan yang menjadi salah satu faktor tingginya angka kecelakaan. Ramburambu lalu lintas yang tidak ada, peletakan bukaan median jalan yang tidak tepat. Analisis EAN dengan nilai BKA dan UCL dimana dari 5 segmen terdapat 3 segmen/Black Site yang merupakan daerah rawan, yaitu KM $0+700-K M 1+400=1248, K M 2+100-K M 2+800=723$ dan KM 2 $+800-K M 3+500=588$, terdapat Black Site yang memiliki nilai paling tinggi diantara lainnya, yaitu Black Spotnya terletak pada segmen $\mathrm{km} 0+700-\mathrm{km} 1+400=1248$. Hasil analisa bahwa tingkat kecelakkan (Rate Of Accident) tertinggi terjadi pada tahun 2020.
\end{abstract}

Keyword: Kecelakaan Lalu Lintas, analisa deskriptif, Bangko.

\section{PENDAHULUAN}

Kabupaten Merangin yang beribukota Bangko merupakan sebuah Kabupaten yang terletak di Provinsi Jambi. Kabupaten ini merupakan salah satu kabupaten tertua dan berkembang pesat di Provinsi Jambi. Jumlah penduduk dikabupaten merangin mencapai lebih dari 500 ribu jiwa. Aktivitas penduduk dikabupaten Merangin mayoritas mata pencarian penduduknya berupa berdagang dan bertani.

Pada tahun 2008 pemerintah kabupaten Merangin mengambil kebijakan berupa mengubah jalan lintas barat sumaterasepanjang 4,2 KM menjadi jalan tiga jalur dalam kota Bangko, pembangunan jalan tiga jalur bertujuan untuk meminimalisir masalahmasalah tranportasi dalam kota dan untuk meningkatkan perekonomian masyarakat yang ada di kota Bangko. Tujuan pembangunan jalur tiga pada awalnya, yaitu:

a. Melancarkan kegiatan bisnis disepanjang jalur tiga.

b. Melancarkan lalu lintas orang dan barang dari kota Bangko maupun dari luar kota Bangko.

c. Mengurangi tingkat kecelakaan pengguna jalan dengan kendaraan menengah dan kecil boleh melewati jalur tiga (dalam kota), sedangkan kendaraan besar dan moda angkutan antar provinsi dan kabupaten dipisahkan atau memakai jalur khusus yang disebut BOR (Bangko Oto Rangruat).

Setelah rampungnya pembangunan jalur tiga di kota Bangko, ada beberapa dampak negatif yang timbul akibat pambangunan ini, salah satunya yaitu, sering terjadi kecelakaan lalu lintas disepanjang jalur tiga yang telah banyak memakan korban jiwa. Menurut pengamatan penulis, hampir setiap pekan bahkan hampir setiap hari terjadi kasus kecelakaan lalu lintas disepanjang jalur tiga baik ringan maupun berat.

Hal ini menjadi permasalahan tersendiri dikota Bangko. Beberapa penyebab seringnya terjadi kecelakaan dapat diketahui seperti permasalahan penegakan aturan lalu lintas, tingkat kesadaran dan kepatuhan penggunan jalan dan kemungkinan faktor konstruksi atau bentuk bangunan jalan atau fasilitas aksesoris pendukungnya sehingga dapat mempengaruhi pengguna jalan yang berakibat pada sering atau tidaknya kecelakaan lalu lintas.

Penelitian ini tujuan untuk mengetahui beberapa point yakni :

1. Mengetahui penyebab terjadinya kecelakaan lalu lintas pada jalur tiga dikota Bangko.

2. Menentukan black spot 


\section{METODE PENELITIAN}

Pada teknik pengolahan data penulis menggunakan penelitian Deskriptif Retrospektif. Deskriptif Retrospektif merupakan suatu metode penelitian yang dilakukan dengan tujuan utama membuat gambaran atau deskripsi tentang suatu keadaan secara objektif dengan melihat kebelakang.

Dalam penelitian ini data kecelakaan lalu lintas adalah data kecelakaan yang didapat dari Unit Laka Lantas Polres Merangin, dengan data tahun 2017-2020. Sementara untuk menghitung dan menentukan tren laju kecelakaan (rate of accident) lalu lintas pada jalur tiga kota Bangko dilakukan analisa dengan membandingkan jumlah kecelakaan yang terjadi dengan panjang jalan $(\mathrm{Km})$ wilayah tinjauan kecelakaan yang dimaksud.

$\mathrm{RA}=\frac{\mathrm{A}}{\mathrm{KM}}$

Keterangan:

$\mathrm{RA}=$ Rate of Accident (laju kecelakaan)

$\mathrm{A}=$ Accident (jumlah kecelakan)

$\mathrm{KM}=$ Kilo Meter (total panjang jalan dalan satuan kilo meter)

\section{HASIL DAN PEMBAHASAN \\ Pengumpulan Data}

Pengumpulan data adalah pengambilan data yang dibutuhkan untuk tugas akhir penulis, adapun data yang dibutuhkan yaitu berupa data primer dan data sekunder.

Data primer dan data sekunder yang diambil oleh penulis adalah, data primer yaitu berupa survey dan pengamatan secara langsung yang dilakukan pada studi kasus penulis, sedangkan data sekunder yaitu berupa data yang telah ada dan penulis dapat dari instansi terkait, seperti data kecelakan dari Unit Laka Lantas kabupaten Merangin dan data jalan yang didapat dari Dinas Pekerjaan Umum kabupaten Merangin.

\section{Pengolahan Data}

Pengolahan data dilakukan setelah semua data yang dibutuhkan terkumpul. Pengolahan data pada penelitian ini terdiri dari sebuah analisa data yang didapat berupa menganalisis data kecelakaan, apa saja penyebab tinginya tingkat kecelakaan akibat pembangunan jalur tiga dikota Bangko, kedua melakukan kajian tentang pembangunan jalur tiga apakah sesuai dengan peraturan atau standar yang telah ada dalam peraturan atau tidak.

\section{Data Survey}

Data survey merupakan data yang didapat secara langsung saat penulis melakukan tinjauan langsung ke lokasi studi kasus yang menjadi objek dalam tugas akhir ini. Survey ini bertujuan untuk mengetahui langsung apa saja kesalahan dalam pembangunan jalur tiga dan untuk mengetahui apa yang menyebabkan tingginya angka kecelakaan pada jalur tiga dikota Bangko. Berikut ini merupakan sebagian dokumentasi dari survey yang dilakukan.

\section{Data Kecelakaan}

Data kecelakaan adalah sebuah data terjadinya kecelakaan yang didapat oleh penulis dari instansi terkait yaitu Unit Laka Lantas Kabupaten Merangin.

Data kecelakaan yang didapat yaitu berupa data banyak terjadinya kecelakaan, jumlah korban luka ringan, luka berat sampai jumlah korban meninggal dunia pertahun yang terjadi di jalur tiga kota bangko. Berikut data kecelakaan pada jalur tiga di kota Bangko.

\section{Pembahasan Hasil}

\section{Data Kecelakaan Pada Jalur Tiga Dikota Bangko}

Data kecelakaan yang dipakai untuk penelitian ini yaitu data dari tahun 2017-2020, data tersebut berisi tentang jumlah kecelakaan, korban meninggal dunia, korban luka berat dan luka ringan, berikut merupakan penjabaran data kecelakaan tersebut.

Tabel 1 Data Kecelakaan

\begin{tabular}{|c|c|c|c|c|c|}
\hline No & Tahun & $\begin{array}{c}\text { Jumalah } \\
\text { Kecelakaan }\end{array}$ & MD & LB & LR \\
\hline 1 & 2017 & 54 & 46 & 13 & 62 \\
\hline 2 & 2018 & 52 & 42 & 16 & 52 \\
\hline 3 & 2019 & 59 & 44 & 8 & 70 \\
\hline 4 & 2020 & 63 & 30 & 10 & 81 \\
\hline \multicolumn{2}{|c|}{ Jumlah } & 228 & 162 & 47 & 265 \\
\hline
\end{tabular}

Sumber: Pengolahan data sekunder (Juli,

2021)

Dari data tabel 1. Dalam kurun waktu 4 tahun (2017-2020) kecelakan yang terjadi dan tercatat di Unit Laka Lantas Kabupaten Merangin sebanyak 228 kasus kecelakaan lalu lintas di jalur tiga kota Bangko yang terdiri dari 162 orang korban meninggal dunia, 47 orang luka berat dan 265 orang luka ringan. Data kecelakaan lalu lintas yang didapat dari 
Unit Laka Lantas Kabupaten Merangin dari tahun 2017 sampai 2020. Data kecelakaan lalu lintas pada jalur tiga di kota Bangko dari tahun 2017-2020 terdapat kenaikan dari setiap tahunnya baik dari jumlah kecelakaan, korban meninggal dunia, korban luka berat maupun korban luka ringan sebagaimana dapat dilihat pada gambar dibawah ini.

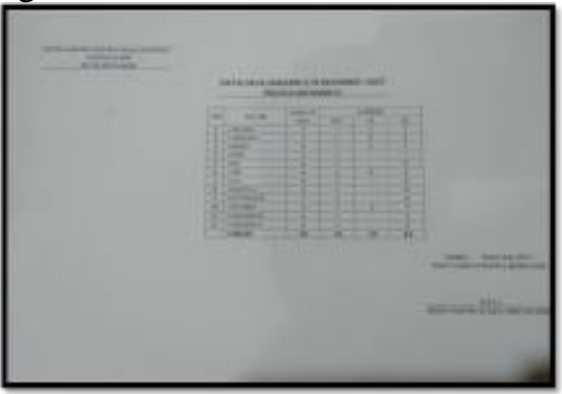

Gambar 1 Data kecelakaan

Sumber: Unit Laka Lantas Kabupaten Merangin

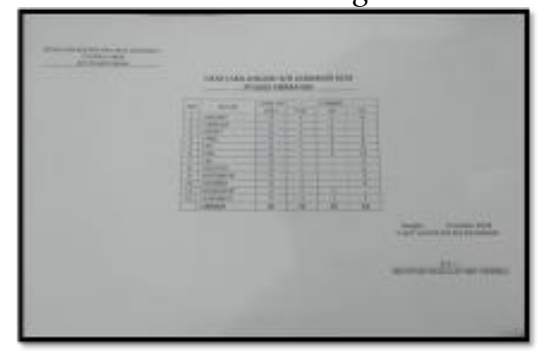

Gambar 2 Data kecelakaan

Sumber: Unit Laka Lantas Kabupaten Merangin

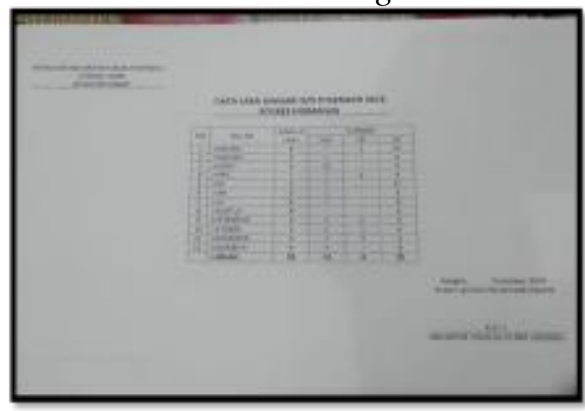

Gambar 3 Data kecelakaan

Sumber: Unit Laka Lantas Kabupaten Merangin

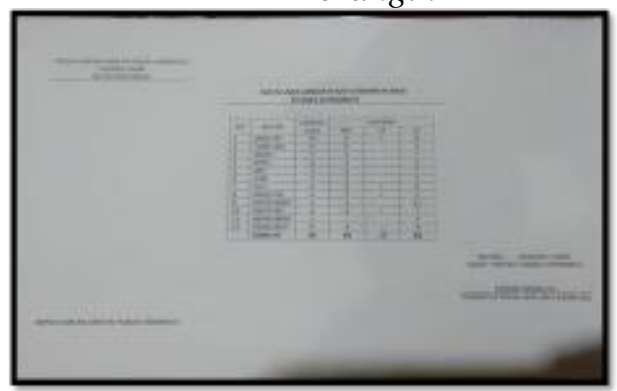

Gambar 4 Data kecelakaan

Sumber: Unit Laka Lantas Kabupaten Merangin
Hasil analisis dapat dinyatakan bahwa tren kecelakaan lalu lintas pada jalur tiga di kota Bangko daritahun 2017 sampai 2020 cenderung naik turun, namun faktor penyebab naiknya tren kecelakaan belum dapat diketahui secara pasti, oleh karena itu untuk mengetahui hal tersebut diperlukan penelitian yang berkelanjutan dan analisis yang lebih mendalam serta perlu melibatkan berbagai pihak antara lain Unit Laka Lantas Kabupaten Merangin dan Dinas Pekerjaan Umum Kabupaten Merangin yang merupakan penyedia data untuk penulis sebagai bahan penelitian ini.

Berdasarkan data statistik yang di dapat dari Unit Laka Lantas Kabupaten Merangin pada gambar diatas, korban kecelakaan lalu lintas yang mendominasi dari seluruh kejadian dalam kurun waktu tahun 2017-2020 adalah korban luka ringan sejumlah 265 korban (55.9\%). Korban kecelakaan lalu lintas berikutnya yang berada pada dalam peringkat kedua adalah korban meninggal dunia sejumlah 162 korban (34.2\%). Sedang yang paling kecil adalah korban luka berat sejumlah 47 korban (9.9\%). Berikut ini merupakan statistik korban kecelakaan pada jalur tiga dikota Bangko dari tahun 2017-2020.

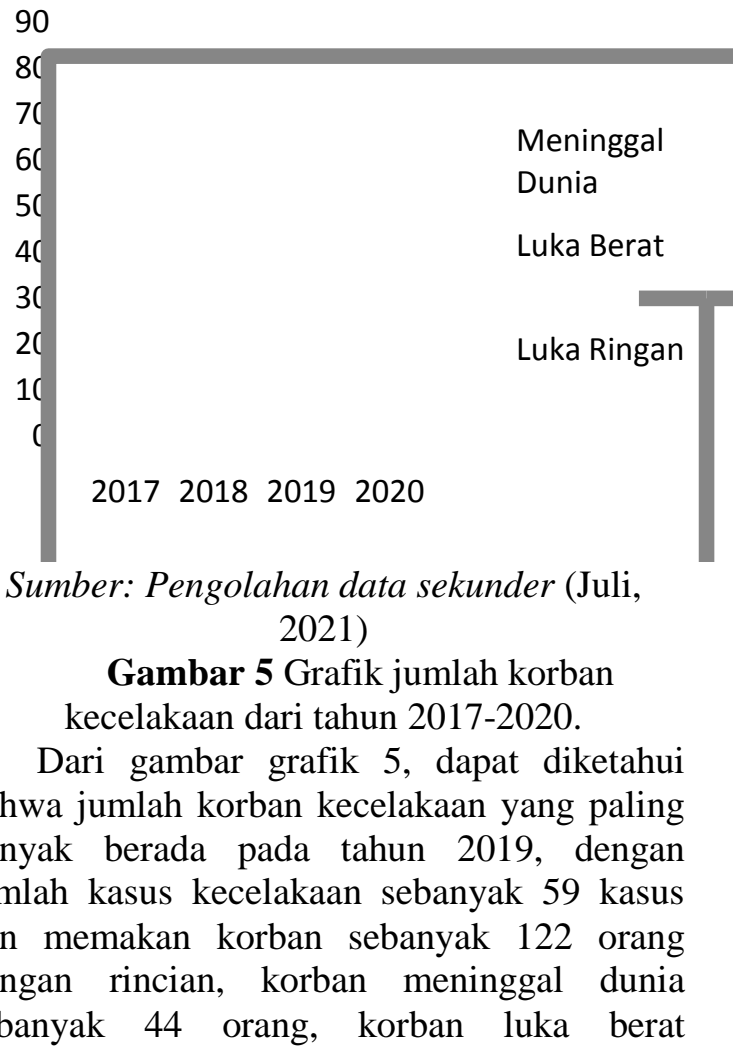


sebanyak 8, dan korban luka ringan sebanyak 72 orang.

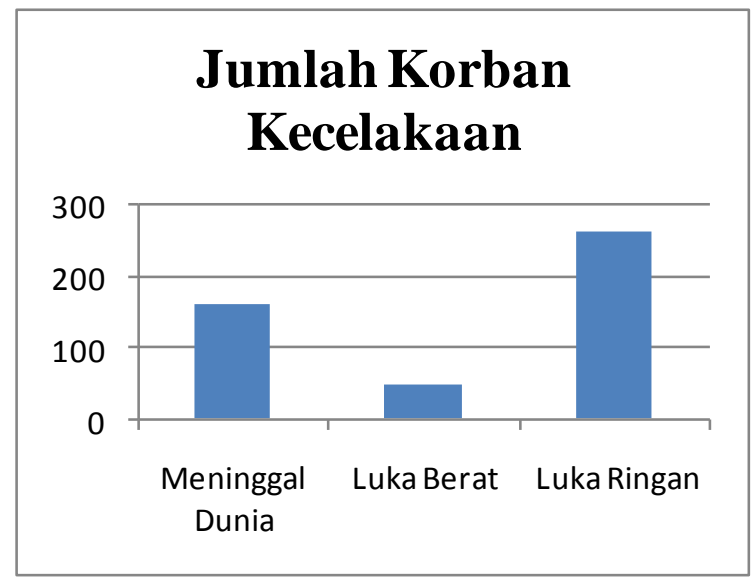

Sumber: Pengolahan data sekunder (Juli, 2021)

Gambar 6. Grafik jumlah korban kecelakaan lalu lintas pada jalur tiga dikota Bangko tahun 2017-2020.

Dari gambar grafik 6, dapat kita simpulkan bahwa kecelakaan yang terjadi pada jalur tiga dikota Bangko dari tahun 2017-2020, jumlah korban luka ringan merupakan paling terbanyak dengan jumlah korban sebanyak 265 orang, sedangkan diurutan kedua terdapat jumlah korban meninggal dunia sebanyak 162 orang dan yang terkecil korban luka berat sebanyak 47 orang.

\section{Kajian Teknik Pembangunan Pada Jalur Tiga Dikota Bangko}

Pada pembahasan ini penulis akan membahas tentang pembangunan pada jalur tiga dikota Bangko apakah telah sesuai dengan peraturan pembangunan yang telah ada atau ada yang tidak sesuai pada peraturan pembangunan yang menyebabkan tingginya tingkat kecelakaan lalu lintas pada jalur tiga dikota Bangko ini.

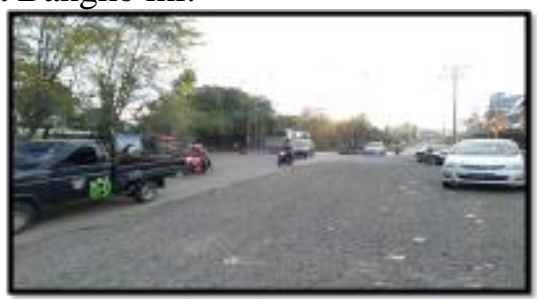

Gambar 7 Jalur tiga dikota Bangko

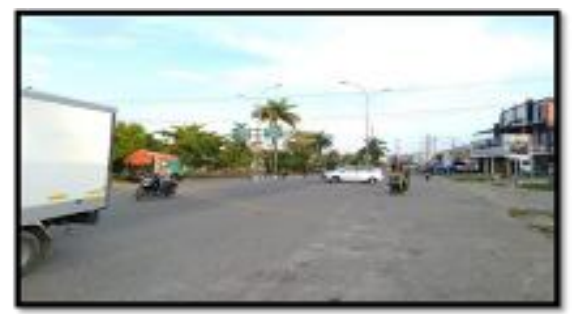

Gambar 8 Jalur tiga dikota Bangko

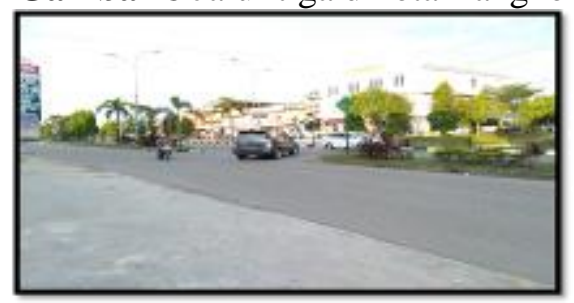

Gambar 9 Jalur tiga dikota Bangko

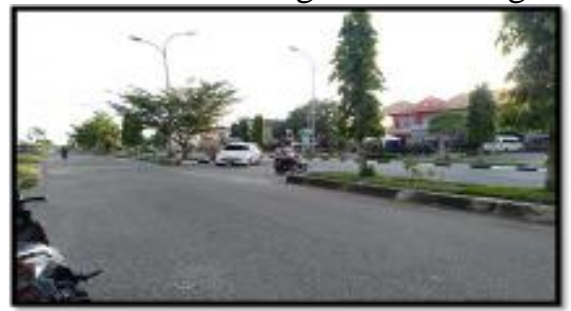

Gambar 10 Jalur tiga dikota Bangko

Gambar diatas merupakan beberapa dokumentasi/gambaran pada jalur tiga dikota Bangko, yang penulis dapat dari hasil survey langsung dilapangan. Dari beberapa dokumentasi tersebut terdapat beberapa kejanggalan yaitu seperti:

1. Rambu-rambu lalu lintas yang tidak ada Rambu-rambu lalu lintas merupakan suatu penunjang yang sangat penting pada jalan, yang berguna sebagai penunjuk arah bagi pengemudi kendaraaan bermotor. Apabila tidak adanya rambu-rambu lalu lintas maka akan menyebabkan kesemerautan atau kekacauan pada jalan tersebut dan juga berakibat kecelakaanlalu lintas karena pengendara bermotor sesuka hati memakai jalan tanpa harus melihat rambu-rambu lalu lintas.

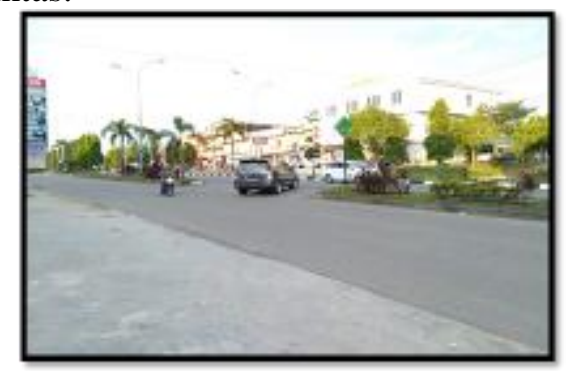

Gambar 11 Rambu-rambu tidak ada

Gambar 11 merupakan salah contoh tidak adanya rambu-rambu lalu lintas yang berada di 
bukaan median jalan. Jadi masalah ini juga merupakan salah satu penyebab kecelakaan lalu lintas pada jalur tiga dikota Bangko.

Peletakan bukaan median jalan yang tidak Tepat Bukaan median jalan merupakan suatu hal yang sangat penting, karena berguna sebagai tempat putar arah dan pindah jalur bagi pengemudi kendaraan bermotor. Dari buku Direktorat Jenderal Bina Marga tentang Perencanaan Putar Balik (U-Turn), ada beberapa ketentuan untuk peletakaan lokasi bukaan median jalan yaitu sebagai berikut:

a. Lokasi di antara persimpangan untuk mengakomodasi gerakan putar balik yang tidak disediakan di persimpangan.

b. lokasi dimana terdapat ruang aktivitas umum penting seperti rumah sakit atau aktivitas lain yang berkaitan dengan kegiatan jalan.

c. lokasi pada jalan tanpa kontrol, merupakan akses dimana bukaan median pada jarak yang optimum disediakan untuk melayani pengembangan daerah tepinya (frontage) dan meminimumkan tekanan untuk bukaan median didepannya. Jarak antar bukaan sebesar 400 sampai 800 meter.

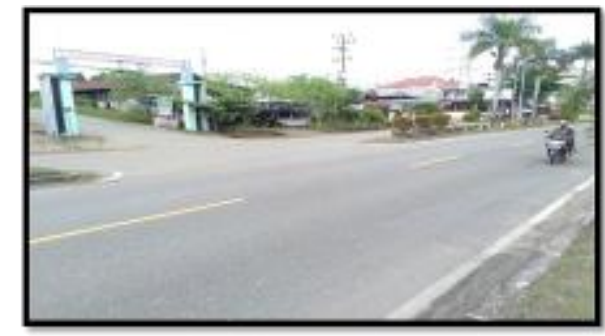

Gambar 12 Peletakan bukaan median yang salah

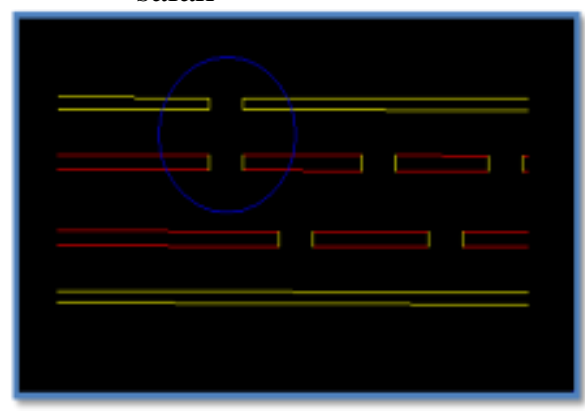

Gambar 13 Autocad jalur tiga

Sumber: Dinas Pekerjaan Umum Kabupaten Merangin

Dari gambar 12 dan 13, dapat disimpulkan bahwa peletakan bukaan median jalan tersebut tidak tepat atau menyalahi aturan karena bukaan median jalan berhadapan langsung dengan simpang jalan masuk kompleks, yang bisa menyebabkan kecelakaan lalu lintas karena kebanyakan pengendara dari jalur tengah langsung masuk kesimpang tersebut tanpa melihat kiri dan kanan dan menyebabkan tabrakan dari samping.

\section{Perhitungan Angka Kecelakaan Lalu Lintas}

Angka kecelakaan lalu lintas adalah suatu angka yang menunjukan tingkat kecelakaan pada suatu ruas jalan. Perhitungan angka kecelakaan pada jalur tiga dikota Bangko (4,2 $\mathrm{KM}$ ) dibuat dalam tabel dengan menggunakan metode yaitu:

1. Angka Kecelakaan Berdasarkan Equivalent Accident Number (EAN)

Untuk menentukan daerah rawan kecelakaan dapat menggunakan Equivalent Accident Number (EAN) dengan mengetahui bobot atas tingkat kecelakaan dengan perbandingan meninggal dunia dikali 12, luka berat dikali 3 dan luka ringan dikali 3. Untuk mengetahui angka EAN pada jalur tiga dikota Bangko dapat dilihat pada perhitungan tabel 2 dan gambar grafik 5.14 berikut ini:

Tabel 2 Bobot Tingkat Kecelakaan Lalu Lintas Pada Jalur Tiga Dikota Bangko (KM 0 $+700-\mathrm{KM} 4+200$ ) berdasarkan niali EAN

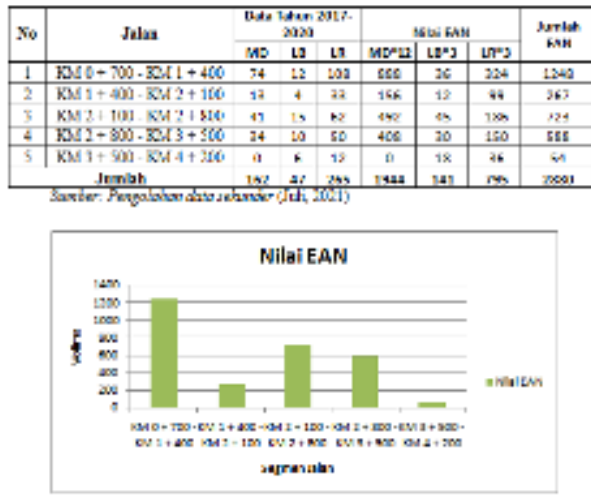

Sumber: Pengolahan data sekunder (Juli, 2021)

Gambar 14 Grafik bobot tingkat kecelakaan lalu lintas pada jalur tiga dikota Bangko (KM $0+700-\mathrm{KM} 4+200$ ) berdasarkan nilai EAN Nilai EAN kritis pada jalur tiga dikota Bangko (KM $0+700-\mathrm{KM} 4+200)$ dapat dihitung sebagai berikut:

$$
\begin{array}{ll}
\text { EANr } & =\text { EAN } / \mathrm{R}=420 / 5=84 \\
\mathrm{EAN} & =\text { Panjang Segmen Terakhir } \\
\mathrm{R} & =\text { Jumlah Segmen } \\
\mathrm{K} & =0,75 \text { (Drajat Kepercayaan) } \\
\mathrm{M} & =\begin{array}{c}
\text { jumlah kejadian/jumlah kendaraan } \\
\quad \text { yang terlibat }
\end{array}
\end{array}
$$




$$
\begin{aligned}
& =228 / 427=0,53 \\
\text { EANc } & =\mathrm{EANr}+\mathrm{K} \sqrt{(\mathrm{EANr} / \mathrm{m})-(0,5 / \mathrm{m})} \\
& =84+0,75 \sqrt{(84 / 0,53)-(0.5 / 0,53)} \\
& =93.41
\end{aligned}
$$

Pada tabel 2 dan gambar grafik 14, menunjukan bahwa berdasarkan EAN terdapat segmen yang memiliki nilai tingkat jumlah korban sangat tinggi. Dimana dari hasil dapat kita ketahui nilai EAN yang paling tinggi yaitu pada titik 1 pada segmen KM $0+700-\mathrm{KM} 1$ + 400 sebanyak 1248 .

\section{Angka Kecelakaan Batas Kontrol Atas}

Nilai batas kontrol atas yang terjadi pada jalur tiga dikota Bangko dimana terdapat jumlah total angka kecelakaan EAN $=2880$ pada 5 segmen pengamatan, maka dapat nilai rata-rata (C) dapat dihitung sebagai berikut:

$$
\begin{aligned}
& \mathrm{C}=\frac{\sum E A N}{\text { jumlah segmen }} \\
& \mathrm{C}=\frac{2880}{5}=576
\end{aligned}
$$

Dengan nilai $\mathrm{C}=576$ maka nilai BKA dapat dihitung sebagai berikut:

$\mathrm{BKA}=\mathrm{C}+3 \sqrt{\mathrm{C}}$

$\mathrm{BKA}=576+3 \sqrt{576}=648$

Tabel 4 Nilai EAN Dengan Batas Kontrol

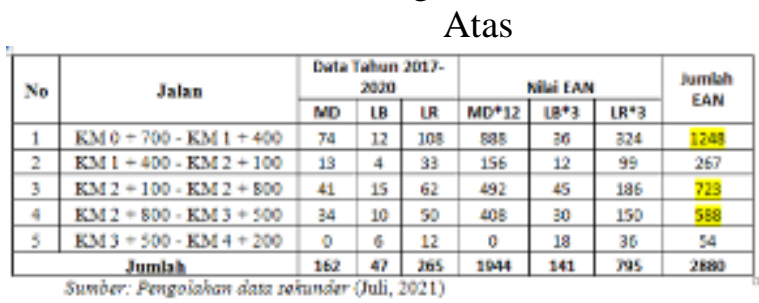

Keterangan: $\square=$ Merupakan nilai EAN yang melebihi batas kontrol atas (BKA) yaitu 576

3. Angka kecelakaan dengan metode statistik kendali mutu upper control limit

Jumlah total angka kecelakaan EAN $=2880$ pada 5 segmen, maka nilai rata-rata $(\lambda)$ dan nilai UCL dapat dihitung sebagai berikut:

$$
\lambda=2880 / 5=576
$$

Faktor probabilitas $(\Psi) \quad=2,576$

Nilai $\mathrm{m}$ (diambil dari no. 1) $=1248$

Maka nilai $\mathrm{UCL}=$

$\mathrm{UCL}=\lambda+\Psi \times \sqrt{ }((\lambda / \mathrm{m})+(0,829 / \mathrm{m})+(1 / 2 \times 1248))$ $=576+2,576 \times$

$\sqrt{\left(\left(\frac{576}{1248}\right)+\left(\frac{0,829}{1248}\right)+\left(\frac{1}{2} \times 1248\right)\right)}$ $=640,37 \approx 640$

Jadi, nilai batas kontrol dengan metode UCL pada jalur tiga dikota Bangko $=640$. Untuk hasil lebih jelasnya dapat dilihat pada tabel 5 .
Tabel 5. Nilai batas kontrol dengan metode upper control limit (UCL)
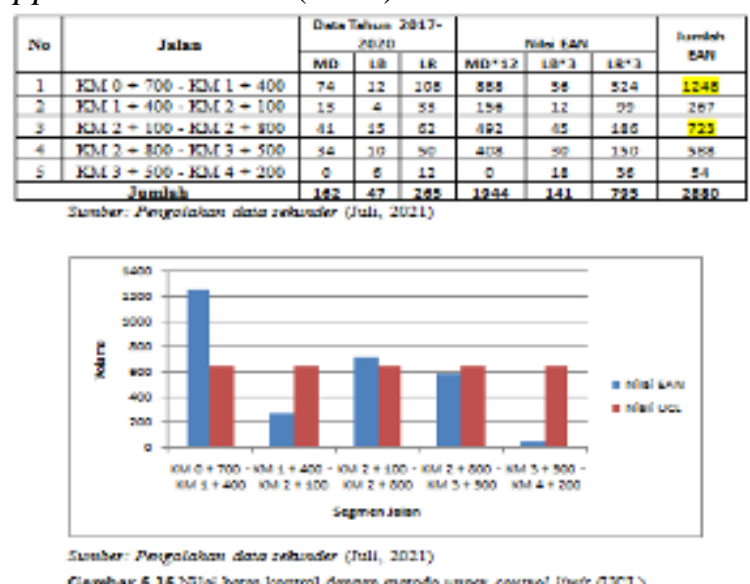

Berdasarkan hasil perhitungan metode BKA dan UCL seperti yang terlihat pada gambar grafik 15, dapat teridentifikasi Black Site. Dikategorikan termasuk daerah rawan apabila nilai EAN melebihi nilai BKA dan UCL. Dari tabel 5 tersebut daerah rawan apabila nilai EAN melebihi BKA 576, dari tabel 5 tersebut terdapat 3 daerah rawan, yaitu: $\mathrm{KM} 0+700-\mathrm{KM} 1+400=1248, \mathrm{KM} 2+$ $100-\mathrm{KM} 2+800=723$ dan KM $2+800-$ $\mathrm{KM} 3+500=588$. Akan tetapi pengidentifikasian daerah rawan dengan metode UCL terdapat 2 daerah rawan dimana

\begin{tabular}{|c|c|c|c|c|c|c|c|c|}
\hline \multirow[t]{2}{*}{ So } & \multirow[t]{2}{*}{ Jalan } & \multicolumn{3}{|c|}{$\begin{array}{c}\text { Drat Thun } 201 \% \text { - } \\
2020 \\
\end{array}$} & \multicolumn{3}{|c|}{ Nis EW } & \multirow{2}{*}{$\begin{array}{l}\text { lumlsh } \\
\text { EN }\end{array}$} \\
\hline & & MO & LB & LR & MO'12 & $1 B^{\prime} 3$ & $1 k^{2} 3$ & \\
\hline 1 & $\mathrm{ED} / 0+700-\mathrm{ED} / 1+400$ & 74 & 12 & 100 & $38 !$ & 36 & 324 & 1248 \\
\hline 2 & $\mathrm{EN} / 2+100 \cdot \mathrm{ED} / 2+000$ & 41 & 15 & 62 & 492 & 45 & 196 & 723 \\
\hline 3 & $\mathrm{EN}: 2+000 \cdot \mathrm{EN} \cdot 3+500$ & 34 & 10 & 50 & 408 & 30 & 150 & 589 \\
\hline
\end{tabular}
Blackspot terjadi apabila nilai EAN melebihi batas nilai UCL, yaitu: KM $0+700-\mathrm{KM} 1+$ $400=1248$ dan KM $2+100-$ KM $2+800$.

\section{Daerah Rawan Kecelakan}

Tabel 6 Daerah rawan kecelakaan lalu lintas berdasarkan nilai BKA dan UCL

Dari tabel 6 diatas adalah kesimpulan dari analisis EAN dengan nilai BKA dan UCL dimana dari 5 segmen terdapat 3 segmen/Black Site yang merupakan daerah rawan. Pada 5 segmen yang telah dianalisis terdapat Black Site yang memiliki nilai paling tinggi diantara lainnya, yaitu pada segmen $\mathrm{km} 0+700-\mathrm{km} 4$ + 200 dimana BlackSpotnya terletak pada km $0+700-\mathrm{km} 1+400$. Pada titik tersebut tingkat kecelakaan sangat tinggi dikarenakan 
kurangnya kesadaran pengguna jalan tentang rambu-rambu yang ada dan sering melanggar, seperti sepeda motor yang memasuki jalur cepat atau jalur tengah padahal jalur tersebut merupakan jalur untuk mobil saja, peraturan telah menentukan bahwa pengendara sepeda motor hanya boleh berkendara pada jalur lambat atau jalur kiri dan kanan dan petugas kepolisian jarang melakukan penjagaan, penjagaan cuma dilakukan pada saat pagi hari, pada saat siang hari tidak lagi ada penjagaan oleh pihak kepolisian dan razia pun dilakukan cuma pada saat ada ada razia rutin yang dilakukan seluruh Indonesia.

\section{Faktor Penyebab Kecelakaan Pada Jalur Tiga Dikota Bangko}

Secara umum dapat dikatakan bahwa suatu kejadian kecelakaan khususnya lalu lintas jalan terjadi akibat dari kumulatif beberapa faktor penyebab kecelakaan. Penyebab tersebut antara lain yaitu faktor manusia/SDM (Sumber Daya Manusia), faktor sarana, faktor prasarana dan faktor cuaca. Selain itu juga ada faktor khusus yang secara tidak langsung dapat berkonstribusi terhadap terjadinya kecelakaan. Kecelakaan dapat timbul jika salah satu dari unsur tersebut tidak berperan sebagaimana mestinya.

Pada dasarnya faktor-faktor penyebab kecelakaan lalu lintas jalan tersebut saling berkaitan atau menunjang bagi terjadinya kecelakaan. Namun, dengan diketahuinya faktor penyebab kecelakaan lalu lintas jalan yang utama, maka dapat ditentukan langkahlangkah penanggulangan maupun rekomendasi untuk menurunkan jumlah kecelakaan. Faktor penyebab kecelakaan lalu lintas pada jalur tiga dikota Bangko dari tahun 2017 sampai dengan tahun 2020 dapat dilihat pada Tabel 7.

Tabel 7 Data jumlah kecelakaan dengan faktor penyebab 2017 S/D 2020

\begin{tabular}{|c|c|c|c|c|c|}
\hline $\begin{array}{c}\text { TAHUN } \\
\text { PENGAMATAN }\end{array}$ & \begin{tabular}{|c|} 
JUMLAH \\
KECELAKAAN
\end{tabular} & $\begin{array}{c}\text { FAKTOR } \\
\text { PENGEMUDX }\end{array}$ & $\begin{array}{c}\text { FAKTOR } \\
\text { KENDARAAN }\end{array}$ & $\begin{array}{l}\text { FAKTOR } \\
\text { CUACA }\end{array}$ & $\begin{array}{l}\text { FAKTOR } \\
\text { JALAN }\end{array}$ \\
\hline 2017 & 52 & 32 & 14 & 2 & 4 \\
\hline 2018 & 51 & 34 & 16 & 1 & 3 \\
\hline 2019 & 59 & 30 & 19 & 4 & 6 \\
\hline 2020 & 63 & 38 & 17 & 3 & 5 \\
\hline JUMLAH & 228 & 134 & 66 & 10 & 18 \\
\hline
\end{tabular}

Adapun hal-hal yang menjadi faktorfaktor penyebab kecelakaan tersebut adalah sebagai berikut:
1. Faktor Manusia atau Sumber Daya Manusia.

Faktor manusia adalah merupakan faktor yang paling dominan dalam kecelakaanlalu lintas pada jalur tiga dikota Bangko, karena manusia sebagai pemakai jalan adalah unsur utama terjadinya pergerakan lalu lintas, selama tahun 2017-2020 kecelakaan yang terjadi oleh faktor manusia sebanyak 134 kasus. Faktor Manusia atau Sumber Daya Manusia yang mempengaruhi kecelakaan pada jalur tiga dikota Bangko ini dapat diidentifikasi dikarenakan dari hal-hal sebagai berikut:

a. Kurangnya kompetensi petugas dilapangan.

b. Rendahnya disiplin pengemudi dalam berlalu lintas.

c. Kurangnya pelatihan bagi pengemudi oleh pemilik kendaraan.

2. FaktorSarana

Sarana transportasi sebagai alat utama untuk memindahkan barang dan manusia dalam hal ini adalah kendaraan. Kendaraan adalah alat yang dapat bergerak di jalan, terdiri dari kendaraan bermotor dan kendaraan tidak bermotor, selama tahun 2017-2020 kecelakan yang terjadi akibat kendaraan yaitu sebanyak 66 kasus. Menurut pasal 1 dari Peraturan Pemerintah No. 44 Tahun 1993 tentang Kendaraan dan Pengemudi, sebagai peraturan pelaksana dari Undang-undang Lalu Lintas dan Angkutan Jalan, kendaraan bermotor adalah kendaraan yang digerakkan oleh peralatan teknik yang berada pada kendaraan itu. Kendaraan bermotor dapat dikelompokan dalam beberapa jenis, yaitu: sepeda motor, mobil penumpang, mobil bus, mobil barang dan kendaraan khusus. Kendaraan bermotor sebagai hasil produksi pabrik telah dirancang dengan nilai faktor keamanan untuk menjamin keselamatan bagi pengendaranya, namun kendaraan akan rentan terhadap pemicu kejadian kecelakaan mana kala prosedur penyiapan/pemeliharaan sebagaimana ketentuan tidak diikuti. Penyimpangan prosedur itu meliputi hal-hal sebagai berikut:

a. Kurangnya perawatan teknis kendaraan oleh pengemudi dan pemilik kendaraan.

b. Kondisi teknik kendaraan yang tidak layak jalan.

c. Kurangnya fasilitas keselamatan dalam kendaraan.

d. Kurangnya pengawasan mengenai kelaikan kendaraan dan ijin beroperasi dilapangan.

e. Penggunaan kendaraan yang tidak sesuai dengan ketentuan (kendaraan dimuati secara berlebihan). 
Untuk faktor sarana harus mendapat perhatian yang sama dengan faktor-faktor lainnya. Karena sarana transportasi jalan yang tidak memadai dapat mempengaruhi sisi psikologis pengemudi pada saat menghadapi situasi darurat.

\section{Faktor Prasarana}

Prasarana sebagai faktor pendukung terselenggaranya transportasi jalan raya seharusnya dibangun dan dipelihara sehingga dapat memenuhi standar keamanan. Dari data tabel diatas diketahui terdapat beberapa kecelakaan lalu lintas pada jalur tiga dikota Bangko yang diakibatkan oleh faktor prasaranan dari tahun 2017-2020 yaitu sebanyak 18 kasus. Beberapa temuan kondisi prasarana transportasi yang memicu timbulnya kecelakaan adalah:

a. Daerah rawan kecelakaan belum ditangani dengan baik oleh regulator.

b. Konstruksi dan geometrik jalan yang kurang sempurna.

c. Kurangnya rambu-rambu lalu lintas, alat penerangan jalan, marka jalan dan alat pemberi isyarat lalu lintas.

4. Faktor Cuaca

Faktor ini merupakan salah satu penyebab kecelakaan pada jalur tiga dikota bangko, kecelakaan lalu lintas yang disebabkan oleh cuaca biasa terjadi karena tidak disengaja, seperti hari hujan yang membuat pandangan pengemudi tidak jelas saat berkendara yang mengakibatkan pengumudi tidak mengetahui pasti kondisi jalan yang akan dilaluinya, selama tahun 2017-2020 kecelakaan yang terjadi oleh faktor cuaca sebanyak 10 kasus.

\section{Laju Kecelakaan (Rate Of Accident) Pada Jalur Tiga Dikota Bangko}

Dari data kecelakaan lalu lintas pada jalur tiga dikota Bangko diatas dan rumus yang ada, akan menganalisis kecelakaan berdasarkan laju kecelakaan (rate of accident), dengan pengukuran laju kecelakaan (rate of accident) maka akan diketahui tingkat keselamatan lalu lintas jalan secara umum. Semakin tinggi laju kecelakaan (rate of accident) maka semakin rendah tingkat keselamatannya. Berikut data panjang jalan pada jalur tiga dikota Bangko yang didapat dari dinas pekerjaan umum kabupaten Merangin.
Tabel 8 Panjang Jalan Jalur Tiga Dikota Bangko

\begin{tabular}{|l|l|l|}
\hline No & Tahun & Panjang Jalan (KM) \\
\hline 1 & 2017 & 4,2 \\
\hline 2 & 2018 & 4,2 \\
\hline 3 & 2019 & 4,2 \\
\hline 4 & 2020 & 4,2 \\
\hline
\end{tabular}

Sumber: Dinas Pekerjaaan Umum Kabupaten Merangin

Dari Tabel 8 diatas dapat dilihat bahwa panjang jalan $(\mathrm{km})$ setiap tahunnya tidak ada pertambahan, dengan mengetahui pertumbuhan panjang jalan setiap tahunnya maka dapat dilakukan penentuan tingkat kecelakaan lalu lintas jalan. Laju kecelakaan (rate of accident) lalu lintas jalan merupakan data kecelakaan yang terjadi pada tahun tertentu dibagi dengan panjang jalan $(\mathrm{km})$ wilayah tinjauan kecelakaan yang dimaksud. Formula yang digunakan dalam mengetahui laju kecelakaan (rate of accident) adalah sebagai berikut: Rate of Accident $=($ Jumlah Kecelakaan/Km Jalan). Untuk lebih lengkapnya gambaran tingkat kecelakaan pada jalur tiga dikota Bangko pada tahun 2017-2020 dapat dilihat pada Tabel 9.

Tabel 9 Laju Kecelakaan (Rate of Accident) Tahun 2017-2020

\begin{tabular}{|c|c|c|c|}
\hline Tahun & $\begin{array}{c}\text { Jumlah } \\
\text { Kecelakaan }\end{array}$ & $\begin{array}{c}\text { Panjang } \\
\text { Jalan } \\
(\mathrm{KM})\end{array}$ & $\begin{array}{c}\text { Laju } \\
\text { Kecelakaan }\end{array}$ \\
\hline 2017 & 54 & 4.2 & 12.9 \\
\hline 2018 & 52 & 4.2 & 12.4 \\
\hline 2019 & 59 & 4.2 & 14 \\
\hline 2020 & 63 & 4.2 & 15 \\
\hline
\end{tabular}

Sumber: Pengolahan data sekunder (Juli, 2021)

Keterangan: Laju kecelakaan (jumlah kecelakaan/KM jalan)

Berdasarkan Tabel 9 diatas, laju kecelakaan (rate ofaccident) lalu lintas pada jalur tiga dikota Bangko empat tahun terakhir (2017-2020) mengalami penurunan dan peningkatan, hal ini dapat terjadi karena beberapa faktor, antara lain:

a. Panjang jalan $(\mathrm{km})$ setiap tahunnya pada jalur tiga dikota Bangko tidak mengalami perkembangan.

b. Meningkatnya jumlah kecelakaan lalu lintas pada setiap tahunnya yang disebabkan oleh berbagai faktor. 
Sepanjang tahun dari tahun 2017 sampai dengan 2020 apabila dilihat secara berurutan per tahun, kecelakaan yang terjadi adalah naik turun. Walaupun naik turun, trennya kebanyakan naik dan jumlah kecelakaan yang terjadi disetiap tahunnya sangat diluar batas wajar. Jadi diharapkan semua pihak dapat ikut berperan untuk menurunkan angka kecelakan disetiap tahunnya.

\section{PENUTUP}

1. Penyebab kecelakaan lalu lintas pada jalur tiga dikota Bangko dari tahun 2017-2020 berdasarkan hasil penelitian terdapat empat faktor yaitu, faktor manusia sebanyak 134 kasus, faktor sarana sebanyak 66 kasus, faktor prasarana sebanyak 18 kasus dan faktor cuaca sebanyak 10 kasus, dapat disimpulkan bahwa faktor manusia atau pengemudi kendaraan menjadi penyebab terbesar tingginya angka kecelakaan pada jalur tiga dikota Bangko, hal ini sebabkan oleh, Kurangnya kompetensi petugas dilapangan, rendahnya disiplin pengemudi dalam berlalu lintas dan Kurangnya pelatihan bagi pengemudi oleh pemilik kendaraan. Jadi kesedaran diri sendiri saat berkendara merupakan suatu hal yang sangat penting dalam keselamatan berkendara.

2. Peletakan bukaan median jalan yang tidak tepat, terdapat beberapa bukaan median jalan terletak berhadapan langsung dengan simpang masuk sebuah kompleks, yang bisa menyebabkan kecelakaan lalu lintas karena kebanyakan pengendara dari jalur tengah langsung masuk kesimpang tersebut tanpa melihat kiri dan kanan dan menyebabkan tabrakan dari samping. Jadi keselahan dalam pembangunan pada jalur tiga dikota Bangko tersebut merupakan salah satu unsur yang membuat tingkat angkat kecelakaan menjadi tinggi.

3. Rambu-rambu lalu lintas yang tidak ada, apabila tidak adanya rambu-rambu lalu lintas maka akan menyebabkan kesemerautan atau kekacauan pada jalan tersebut dan juga berakibat kecelakaan lalu lintas karena pengendara bermotor sesuka hati memakai jalan tanpa harus melihat rambu-rambu lalu lintas.

4. Blackspot, dengan mengunakan analisa perhitungan Equivalent Accident Number (EAN). Nilai EAN yang didapat, dan menggunakan patokan dari nilai BKA dan UCL yang telah didapat, didapatkan hasil dari 5 segmen yang ada terdapat 3 segmen/Black Site yang merupakan daerah rawan, yaitu KM $0+700-\mathrm{KM} 1+400=$ $1248, \mathrm{KM} 2+100-\mathrm{KM} 2+800=723$ dan $\mathrm{KM} 2+800-\mathrm{KM} 3+500=588$, dan terdapat Black Site yang memiliki nilai paling tinggi diantara lainnya, yaitu BlackSpotnya terletak pada segmen $\mathrm{km} 0+$ $700-\mathrm{km} 1+400=1248$.

\section{DAFTAR PUSTAKA}

Anton Gazali Thoib. Nico Bakista Satriawan. Bambang Riyanto. Kami Hari Basuki. (2014). Analisis Kecelakaan Lalu Lintas Dengan Metode Angka Kecelakaan Berbasis Panjang perjalanan Kendaraan Total (Studi Kasus: Jalan SiliwangiWalisongo, Semarang Km Smg 7+200-Km Smg 8+100). Jurnal Karya Teknik Sipil. Vol 3. No. 3.

Casado-Sanz, N., Guirao, B., \& Attard, M. (2020). Analysis of the risk factors affecting the severity of traffic accidents on spanish crosstown roads: The driver's perspective. Sustainability (Switzerland), 12(6).

https://doi.org/10.3390/su12062237

Departemen Perhubungan Republik Indonesia. (2006). Jenis kecelakaan lalu. Jakarta.

Hidayati, A. Y. H. L. (2016). Analisis Risiko Kecelakaan Lalu Lintas Berdasar Pengetahuan, Penggunaan Jalur, Dan Kecepatan Berkendara. Berkala Epidemiologi, vol.4, No.(July 2016), 275-276.

https://doi.org/10.20473/jbe.v4i2.2016.27 5

Intari, D. E., Kuncoro, H. B. B., \& Pangestika, R. (2019). ANALISIS KECELAKAAN LALU LINTAS DAN BIAYA KECELAKAN MATERIL PADA RUAS JALAN NASIONAL ( Study Kasus: Jl. Raya serang Km 23 Balaraja - Jl. Raya Serang Km 35 Jayanti Kabupaten Tangerang ). Jurnal Fondasi, 8(1), 5260. https://doi.org/10.36055/jft.v8i1.5401

Jusuf, A., Nurprasetio, I. P., \& Prihutama, A. (2017). Macro data analysis of traffic accidents in Indonesia. Journal of Engineering and Technological Sciences, 49(1), 133-144. 
https://doi.org/10.5614/j.eng.technol.sci.2 017.49.1.8

Kementrian pekerjaan umum dan perumahan rakyat Nomor 43. (2016). Rambu, Marka dan Delineasi. Diklat Jalan Berkeselamatan. Jakarta.

Muthusamy, A. P., Rajendran, M., Ramesh, K., \& Sivaprakash, P. (2015). A review on road traffic accident and related factors. International Journal of Applied Engineering Research, 10(11), 2817728183.

Undang-undang Republik Indonesia, U. R. (2009). lalu lintas dan angkutan jalan Peraturan Pemerintah Republik Indonesia nomor 43. (1993), prasarana jalan raya dan lalu lintas.

Rofifah, D. (2020). 済無No Title No Title No Title. Paper Knowledge. Toward a Media History of Documents, 3, 12-26.

Sigit Puji Santosa, Andi Isra Maahyuddin and Febrianto Guntur Sunoto. (2017). Anatomi Of Injury Severity and Fatality In Indonesian Traffic Accidents. J. Eng. Technol. Sci. Vol 4. No. 3. 412-422.

Utomo, N. (2012). Analisa Faktor Penyebab Kecelakaan Lalu Lintas Pada Segmen Jalan By-Pass Krian-Balongbendo (Km. 26+000-Km. 44+520). Jurnal Teknik Sipil KERN, 2(2), 73-84. Retrieved from http://ejournal.upnjatim.ac.id/index.php/k ern/article/download/1370/1135

Pratiwi, Y. Y., \& Siahaan, F. C. (2017). Accident Among Children in Indonesia Urban Areas. Accident Among Children in Indonesia Urban Areas, 3(2), 79-92.

Zanuardi, A., \& Suprayitno, H. (2018). Analisa Karakteristik Kecelakaan Lalu Lintas di Jalan Ahmad Yani Surabaya melalui Pendekatan Knowledge Discovery in Database. Jurnal Manejemen Aset Infrastruktur \& Fasilitas, 2(1), 45-55. https://doi.org/10.12962/j26151847.v2i1. 3767 